\title{
Arteriovenous uterine malformation: case report
}

\author{
Raúl D. Lara Sánchez ${ }^{1 *}$, Alexander J. Rafaelano Miranda1, Sara E. Hernandez Flores², \\ Tania P. Alvarez ${ }^{3}$, Jose M. Bizuet Cabrera ${ }^{3}$, Angel Lemus Huerta ${ }^{4}$
}

\begin{abstract}
${ }^{1}$ Department of Gynecology and Obstetrics, Postgraduate School of Naval Sanity, Universidad Naval and the Centro Médico Naval, Secretaría de Marina Armada de México (SEMAR). Ciudad de México, México

${ }^{2}$ Department of Gynecology and Obstetrics, the Centro Médico Naval, Secretaría de Marina Armada de México (SEMAR). Ciudad de México, México

${ }^{3}$ Department of Pathology, Centro Médico Naval, Ciudad de México, México

${ }^{4}$ Department of Human Reproduction, Centro Médico Naval, Ciudad de México, México
\end{abstract}

Received: 05 October 2019

Revised: 03 December 2019

Accepted: 09 December 2019

\section{* Correspondence:}

Dr. Raúl D. Lara Sánchez,

E-mail: danievan0910@gmail.com

Copyright: (C) the author(s), publisher and licensee Medip Academy. This is an open-access article distributed under the terms of the Creative Commons Attribution Non-Commercial License, which permits unrestricted non-commercial use, distribution, and reproduction in any medium, provided the original work is properly cited.

\begin{abstract}
The case of a 49-year-old patient is reported, with a particular history of obstetric risk, who presented with severe transvaginal hemorrhage, was performed doppler arteriography and ultrasound, finding data suggestive of arteriovenous uterine malformation, surgery was decided due to heavy menstrual bleeding with anemia, the pathology report shows characteristics of an arteriovenous uterine malformation.
\end{abstract}

Keywords: Arteriovenous, Fistula, Intramiometrial, Malformation, Shunts, Uterine

\section{INTRODUCTION}

The uterine arteriovenous malformation (MAVU) is also called arterio- uterine fistula or cirsoid aneurysm. They are varicose, arteriovenous dilatations intramiometrial, without capillary involvement. They are classified as congenital and acquired. It is one of the causes of abnormal uterine bleeding, its definitive treatment is hysterectomy, currently selective embolization could be a treatment as an option in patients seeking to preserve fertility. ${ }^{1-3}$

There are about 100 cases, sometimes reported as arteriovenous uterine fistulas in a review of Panagiotis. They present about $85 \%$ after a uterine trauma, dilation and curettage. It represents $1-2 \%$ of genital and intraperitoneal hemorrhage. In a number of MAVU cases,
$96 \%$ were diagnosed in the premenopause and only $4 \%$ in the postmenopause..$^{4-7}$

\section{CASE REPORT}

Female of 49 years of age, gestations 2, caesarean sections 2, 26 and 24 years ago, menarche at age 12, who comes for consultation for the first time, manifesting history of heavy transvaginal bleeding with regular cycles but with more than 8 towels a day, of a year of evolution accompanied by attack on the general state, weakness, fatigue, paleness, palpitations and dyspnea of small efforts. Upon examination paleness of teguments, to the uterus touch in anteroversoflexion, $13 \mathrm{~cm} \times 6 \mathrm{~cm} \times 7 \mathrm{~cm}$. It has hematic biometrics with hemoglobin of $7 \mathrm{~g} / \mathrm{l}$, hematocrit of $24 \%$, platelets of 378000 , urea of 42 , creatinine of $0.8 \mathrm{mg} / \mathrm{dl}$, low serum iron of 18 , normal 
coagulation times. Ultrasound with the following findings (Figure 1).

Management is decided by intramuscular iron hemoglobin $9.7 \mathrm{~g} / 1$ per month is achieved with hc to $30 \%$, starts menstrual bleeding, because it presents severe bleeding in course of their next menses má s 8 towels are decide opting for surgical management is performed total abdominal hysterectomy, minimal trans operative bleeding, surgical piece is sent to study with the findings reported in (Figure 2,3) he is currently in full recovery.

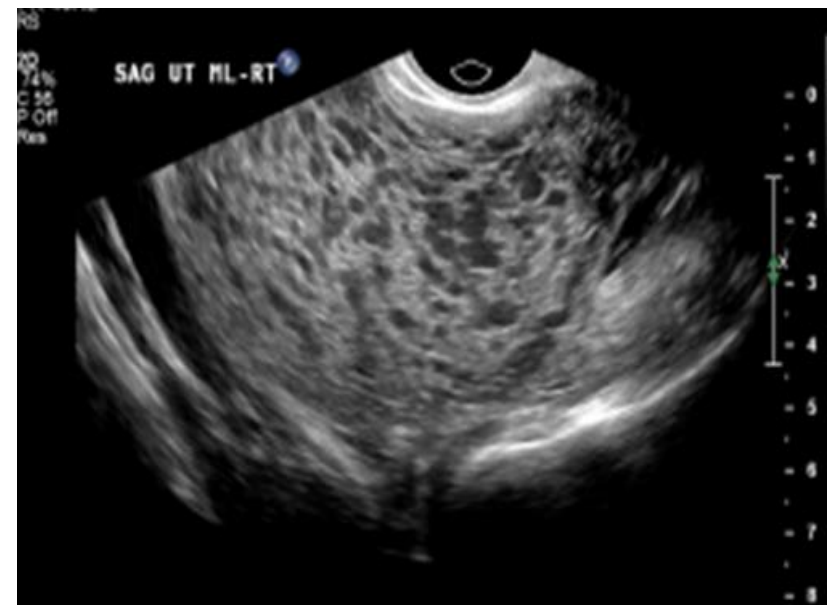

Figure 1: US endovaginal: Myometrium of heterogeneous appearance at the expense of multiple anechoic areas of sinusoidal morphology (cystic aspect). Hypoechoic, tortuous areas at the myometrial level. Multiple images of tubular appearance (hypoanechoic), of variable size, of myometrial and endometrial localization, as well as focal thickening of the myometrium.

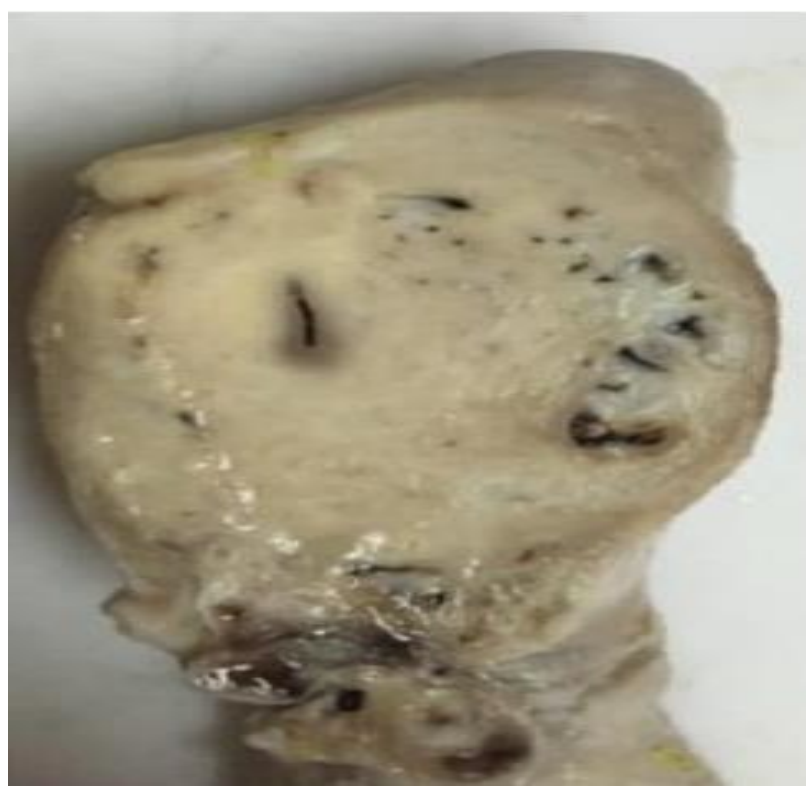

Figure 2: Macroscopic study of MAVU. Uterine wall with dilated blood vessels within myometrium that expand in the body and fundus portion.

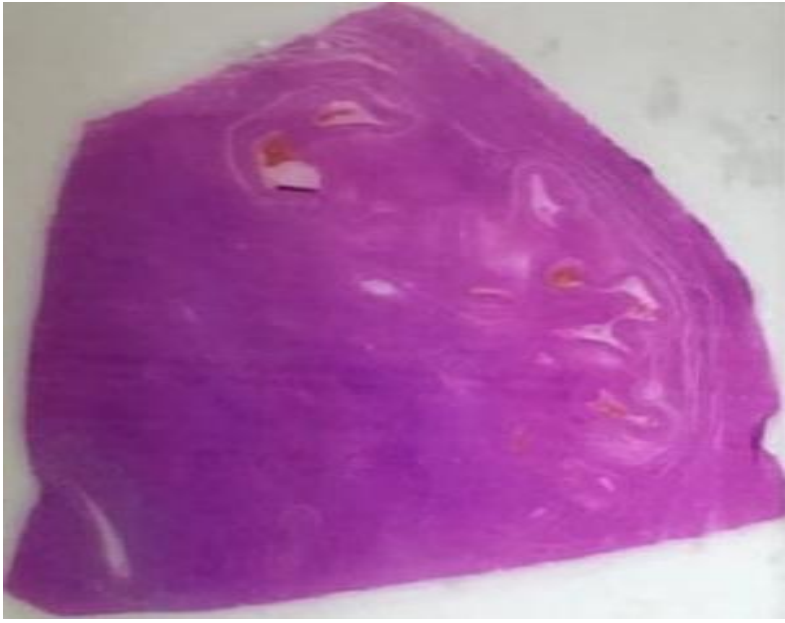

Figure 3: Histopathological study MAVU. There are thick-walled, ectatic blood vessels immersed in the adjacent myometrium.

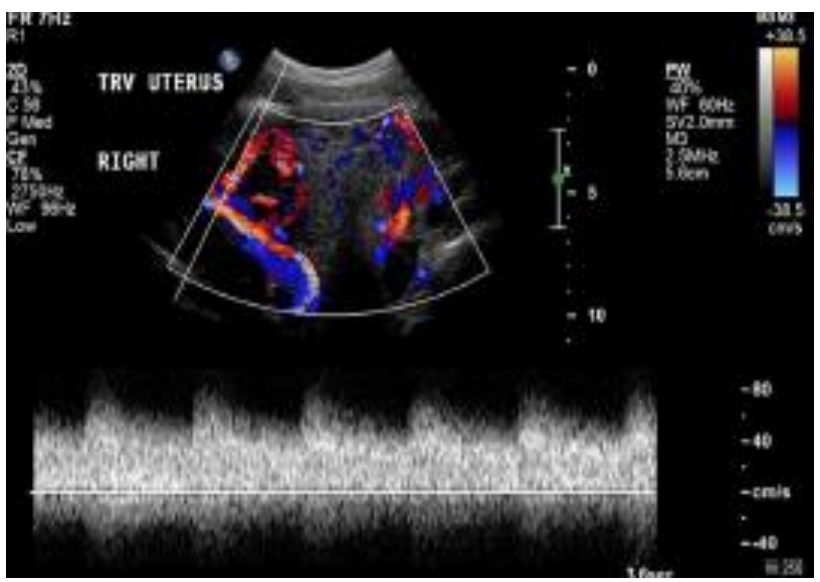

Figure 4: MAVU doppler ultrasound. Vascular structures of low resistance (type shunt A-V), with low resistance indices and high-speed flows.

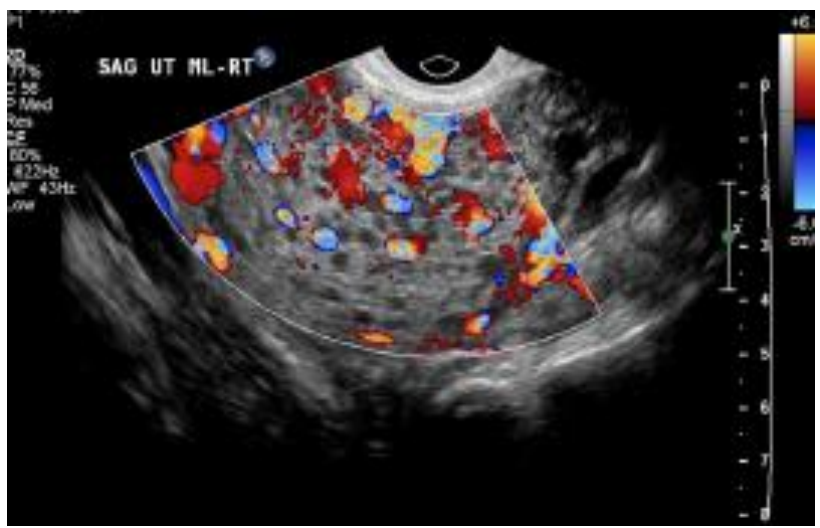

Figure 5: Doppler with MAVU: Intense vascularity (which translates into a flow of high-speed systolic turbulence with a bidirectional component during diastole), which leads to a pathology with important vascular component (important to determine differential diagnosis with Mola de invasive type or hyper vascular tumors). 


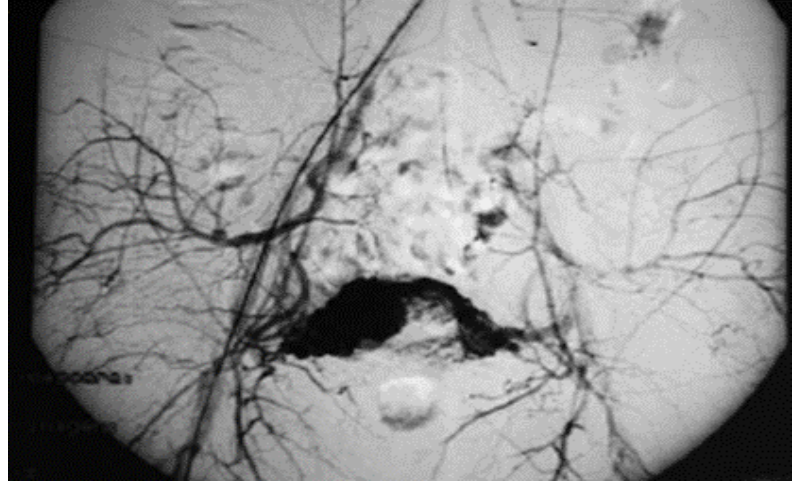

Figure 6: Arteriography of MAVU. Irregular vascular spaces that show high vascular flow. There are thickwalled, ectatic blood vessels immersed in the adjacent myometrium.

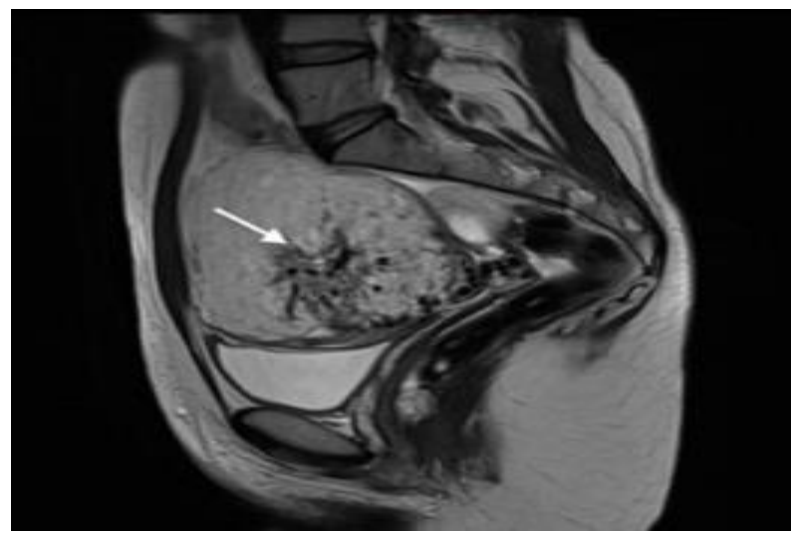

Figure 7: RNM of MAVU. Sequences enhanced in T1 and T2, as well as T1 + Gadolíneo. (Arrow) Tubular images of tortuous appearance with absence of signal, located in the myometrium and parametrium that tend to protrude towards the endometrial cavity.

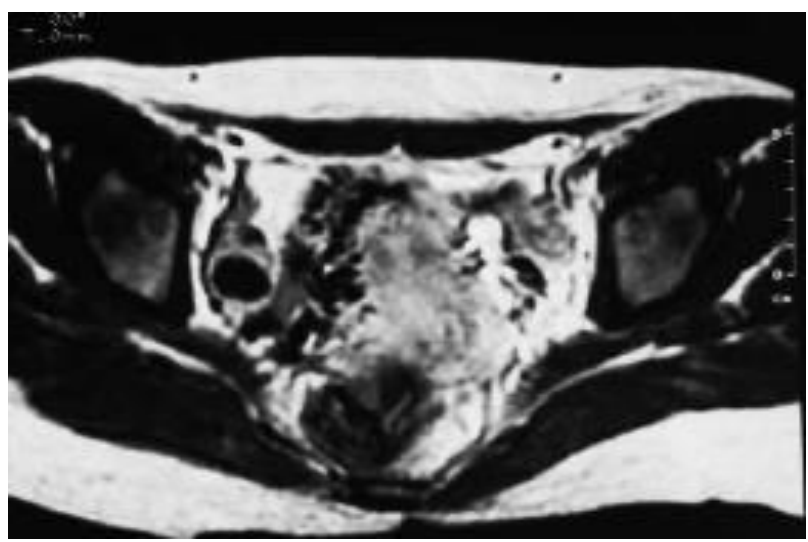

Figure 8: Dynamic sequences with contrast: They reveal intensity of uptake equal to that of vascular structures, which is called vascular nest (which presents early venous return and shows intense enhancement after the administration of Gadolíneo). Vascular nest: A cluster of vessels with high flow, fed by the uterine artery and draining through the parauterine veins.

\section{DISCUSSION}

Acquired MAVU occurs when a venous sinus is incorporated into a scar process of the myometrium after chorionic hair necrosis, in patients undergoing caesarean section or uterine curettage, it can reverse spontaneously. It can occur as a congenital malformation due to poor differentiation of the vascular primordium in a definite artery or vein..$^{1,8}$

It can arise after pregnancy, molar pregnancies or tumors of the placental bed, such as accreta or gestational trophoblastic disease, porterior to traumatic births, myomectomy, resectomies, endometrial or cervical cancer, exposure to diethyl ethylbestrol and infections. $85 \%$ of patients with arteriovenous uterine malformation had dilation and uterine curettage after a miscarriage, only $8 \%$ due to abnormal uterine bleeding and $8 \%$ due to elective abortion. ${ }^{1,7,9,10}$

Clinical symptoms can vary from asymptomatic, chronic pelvic pain, dysfunctional uterine bleeding, infertility due to recurrent abortion, hypovolemic shock and hematuria. They may be accompanied by hypermenorrhea or pelvic congestion syndromes, so their frequency may be higher. The acquired patients have intermittent but very severe hemorrhages, which suggest an arterial cause. Almost all the cases present severe hemorrhages between the 1st and 6th month after surgical act curettage or cesarean section. Other cases associated with preterm birth occur with persistent uterine bleeding. No obstetric history will be more focused on a congenital case. ${ }^{1,2,7}$

The hemorrhages described secondary to this malformation can be so severe that they cause hypovolemic shock, they can be associated with persistent chorionic gonadotropin hormone levels below 20 IU/l. ${ }^{2,11}$

\section{Diagnosis}

It is possible to diagnose it in the immediate puerperium postpartum by Doppler ultrasound, they are used for its best characterization, ultrasound, computed tomography, magnetic resonance, Hysteroscopy. Angiography establishes the diagnosis and limits the lesion. Transvaginal ultrasound shows in 65 and 35\% irregular, ill-defined spaces. Concentrated in case of being congenital and diffuse in the acquired ones. Similar to adenomyosis, they can be reported as angiomas, destructuration of the uterine wall, heterogeneous echoestructures, anechogenic areas of sinusoidal morphology, uterine arteriovenous malformation and in the case of immediate puerperium up to invasive trophoblastic disease, as a last option of diagnosis hypervascularized myometrial tumor. . $^{1,3,11}$

In the doppler there can also be yellow areas, vascular ball present in $95 \%$ of the cases (Figures 4), high flow velocities and low resistances, there are bidirectional 
flows characteristic of shunts or arteriovenous fistulas (Figure 5) Small economic areas myometrial cells are color-coded because they are characteristically vessels and in adenomyosis this pattern is not found. They have been reported as a tumor with a mosaic pattern of their vasculature, however they can be confused as remains of conception. ${ }^{12,13}$

By hysteroscopy in a case report a mass occupying the uterine cavity in the uterus fundus of approximately $3 \mathrm{~cm}$ can be seen, highly vascularized and friable on contact, so it was not treated by this means. ${ }^{8}$ In magnetic resonance studies, multiple tortuous and dilated vessels have been described that occupy the entire thickness of the myometrium, where they penetrate into the endometrium, including involvement of the parametrial area without observing any tumor other than the vessels described, the same descriptions compatible with MAVU. The arteriography allows detecting the type of lesion, observing this malformation as a hypertrophic, tortuous arterial tumor with large collateral arteries (Figure 6). Magnetic resonance imaging and helical computed tomography allow us to avoid invasive studies such as arteriography (Figure 7, 8). The magnetic angioresonance shows the vascular anatomy, the vessels and the abnormal hemodynamic flows, allowing confirmation of the diagnosis. Histopathology reports show angiomatous tissue, exuberant and congestive vessels, microscopically extensive arteriovenous angiomatosis, presence of deciduous in the media and trophoblastic cells in stroma and vessels, immunohistochemistry shows placental accreta, typical of gestational trophoblastic disease in patients with hysterectomy with accretion at 34 weeks. ${ }^{1,2}$ In an induced abortion vaginal ultrasound with myometrial arteries and veins, periovarics, in the plexus of santorini and towards the abdomen, varicose plexus that affects myometrium, uterine vessels to aorta, with resolution by hysterectomy was reported.

\section{They are classified as congenital and acquired}

\section{The congenital tend to show}

- Multiple nutritional arteries

- A ball of vessels with arterial and venous histological characteristics

- Numerous drainage veins.

- There may be other vascular malformations in the rest of the body.

\section{The acquired ones tend to present}

- Myometrial fistulas between arterial and venous branches

- They have arteries coming from normal internal iliac arteries

- Without vascular extra to the uterine and they present characteristic ball

- Generally, they are isolated.
Among the treatments used include selective embolization, hysterectomy, medical treatments and laparoscopic management. ${ }^{2,10}$

The decision of treatment with embolization is related to the clinical severity and availability of the technique, the embolization criteria used are:

Clinical metrorrhagia with negative or negativized BHGC.

\section{Ultrasound}

Vascular bundle with multidirectional flow, curves with high systolic velocity peaks and low resistance and pulsatility indexes.

\section{Radiological}

\section{Whenever it has been feasible RNM and / or TAC., ${ }^{1,2}$}

The most common treatment in a series of cases was selective embolization in 59\%, total abdominal hysterectomy (HT) in 29\%, spontaneous resolution in $6 \%$, relapse after selective embolization $17 \%$ and pregnancy rate after treatment of the $27 \%$ The agents used for embolization were: gel foam, polyvinyl alcohol, staples in 6 cases, gelatin tris-acril-gelatin, isobutyl cyanoacrylate, acrylic polyamide, ethanol and histoacryl. Ligatures were used in the internal iliac artery, vessels of the MAVU and uterine artery. The instrumented curettage has adverse results and delay in definitive treatment. We report a case of a patient with two previous deliveries, later a gestational loss, who underwent ameus and application of a device with intrauterine levonorgestrel, after two months she presented with more abundant uterine bleeding, occlusion of the internal iliac artery was performed. laparoscopic route by MAVU, with referral per month. In postmenopausal patients conservatively, uterine artery ligation has been used after a successful selective embolization. A case identified as persistence of ovular debris by ultrasound, subsequently addressed as MAVU, was managed with progestogens in which the malformation reverted at 6 months. ${ }^{1,2,4,7,8}$

A review of 30 cases of infertility associated with MAVU achieved pregnancy after arterial embolization treatment. Delotte et al, reported 13 pregnancies after arterial embolization, with 13 births, 1 placenta previa, two postpartum hemorrhages, managed medically, the cesarean in this group was $38.5 \%$. The use of transcatheter embolization of the uterine artery offers a safe and effective alternative to hysterectomy surgery, favoring fertility. Embolization reports pregnancy in $69 \%$ of cases associated with structural pathology in other reviews, in this review of 30 cases pregnancy was achieved in $43.3 \%$ of cases with $100 \%$ of births. ${ }^{7,9,11,14}$

Hasbun et al, report in 3 anemias secondary to bleeding from MAVU of up to $8.2 \mathrm{~g} / \mathrm{dl}$, as well as hematocrit of 
$25 \%$, management with previous embolization 24 hours, subsequent subtotal hysterectomy, discharge at 4 days without complications. In another case, embolization is performed obtaining a $70 \%$ reduction in flow, evolving with cessation of bleeding, without requiring uterine curettage and discharge after 2 days, in another case selective embolization of internal iliac arteries, supraselective catheterization of uterine arteries and embolization. achieving vascular stance, good tolerance, cessation of bleeding and discharge after 3 days..$^{15}$

Cases associated with placental retention and placenta previa are reported with a report of MAVU at the cervical level without evidence of trophoblastic disease. There are case reports associated with gestational trophoblastic disease, which are presented even after the adequate response of chemotherapy with EMA-CO at 3 months, resolved by arterial embolization, presenting pseudoaneurysm of the femoral artery by catheterization, without recurrence to 11 months of follow-up with pharmacological management based on oral contraceptives. ${ }^{16-18}$

Two patients reported severe vaginal bleeding in pregnancy and 2 in the immediate postpartum. 50\% received blood transfusions, $1 \%$ of patients suffered thromboembolism after HTA, managed successfully with anticoagulants, $1 \%$ died from drugs secondary to the anesthetics used. An obstetric hysterectomy was reported due to heavy bleeding in the first trimester. Patients treated with selective arterial embolization report successes of 75 to $93 \%$. However, only $57 \%$ report success in the first procedure, up to $32 \%$ require reoperation, the time between each is not specified and is based on the recurrence of the symptoms or the persistence of the same. ${ }^{1,8,10}$

Interventional radiology treatments based on infusion of DMSO and Onyx embolization have been reported 3 weeks later, radiological control at 24 hours with areas without enhancements showing necrosis postembolization area. High at 48 hours. Control a month with regular menstruation, ultrasound of control with hyper refrigerant areas, no doppler capture, corresponding to embolized MAVU, with controls until complete resolution of ultrasound image. ${ }^{19}$

\section{CONCLUSION}

MAVU may be associated with hemorrhage in pre and postmenopausal stages of a woman, an adequate approach and identification of this pathology may decrease the mortality rate, as well as avoid hysterectomies in patients with infertility or without satisfied parity, decreasing the rate of hysterectomized nulliparous patients, so it is necessary to evaluate with doppler ultrasound and characterize these lesions confirmed by angiography or helical CT scan, to offer the best management that at the moment seems to be by selective arterial embolization.
Funding: No funding sources

Conflict of interest: None declared

Ethical approval: Not required

\section{REFERENCES}

1. Rodríguez A, Escartín I, Riazuelo G, Zaragozano R. Uterine arteriovenous malformation as a rare cause of genital bleeding. Radiol Elsevier. 2002;44(2):813.

2. Eduardo L, Raga F, Chagas K, Bonilla F, Carlos J. The uterine arteriovenous malformation, a more frequent and serious lesion than suspected. Obstet Gynecol. 2010;53(1):10-7.

3. Yoon DJ, Al Taani J, Dowell JD. Uterine arteriovenous malformation: pathophysiology, procedural management, and outcomes. J Vas Inter Radiol. 2014;3(25):S171-2.

4. Mekaru K, Oishi S, Akamine K, Heshiki C, Aoki Y. Spontaneous regression of uterine arteriovenous malformations with conservative management. Case Reports in Obstetrics and Gynecology. 2017:1-6.

5. Capmas P, Legendre G, Fernandez H. Laparoscopic management of uterine arteriovenous malformation via occlusion of internal iliac arteries. J Minim Invasive Gynecol. 2016;19(6):785-8.

6. Rodríguez-blas AI, Díaz-garcía JD, Naples-medina S, Hernández-leal M, Casián-castellanos GA. Uterine arteriovenous malformation. Revista del Hospital Juárez de México. 2018;85(2):100-4.

7. Peitsidis P, Manolakos E, Tsekoura V, Kreienberg R, Schwentner L. Uterine arteriovenous malformations induced after diagnostic curettage: a systematic review. Arch Gynecol Obstet. 2011;284(5):1137-51.

8. Alonso Pacheco L, Rodrigo Olmedo M, Narbona Arias I, Hijano Mir JV. Uterine arteriovenous fistulas after curettage. Hysteroscopic management Obstet Ginecol Progress. 2014;57(3):126-9.

9. Maleux G, Timmerman D, Heye S, Wilms G. Acquired uterine vascular malformations: radiological and clini- cal outcome after transcatheter embolotherapy. Eur Radiol. 2006;16:299-306.

10. Calzolari S, Cozzolino M, Castellacci E. Uterine arteriovenous malformation: hysteroscopic identification is possible. J Minim Invasive Gynecol. AAGL. 2016;23(3):293-4.

11. Darwish B, Letailleur M, Dietrich G, Roman H. Hysterectomy for uterine arteriovenous malformation. Laparoscop View. 2016;2015-6.

12. Tullius TG, Ross JR, Flowers M, Ghaleb M, Kupesic Plavsic S. Use of three-dimensional power Doppler sonography in the diagnosis of uterine arteriovenous malformation and follow-up after uterine artery embolization: Case report and brief review of literature. J Clin Ultrasound. 2015;43(5):327-34.

13. Aseeja V, Kaur T, Taneja BK. Arterio-venous malformations and retained products of conception: a case report and brief review arterio-venous malformations and retained products of conception: a 
case report and brief review. Webmed Central Obstet Gynaecol. 2011;2(9):1-5.

14. Mohan PP, Hamblin MH, Vogelzang RL. Uterine artery embolization and its effect on fertility. J Vasc Interv Radiol. 2013;24(7):925-30.

15. Hasbun J, Palavecino P, Segura P, Chavez I, Burgos $\mathrm{N}$, Tobar $\mathrm{H}$, et al. Uterine arteriovenous malformation and obstetric hemorrhage: diagnosis and management in three clinical cases. Chilean J Obstet Gynecol. 2014;79(3):199-208.

16. Roach MK, Thomassee MS. Acquired uterine arteriovenous malformation and retained placenta increta. Obstet Gynecol. 2015;126(3):642-4.

17. Touhami O, Gregoire J, Noel P, Trinh XB, Plante M. Uterine arteriovenous malformations following gestational trophoblastic neoplasia: A systematic review. Eur J Obstet Gynecol Reprod Biol. 2014;181:54-9.
18. Aal AKA, Estafanous MW, Estafanous LA, Oser R, Saddekni S, Underwood E, et al. Educational Exhibit Abstract No. 429 Endovascular management of uterine arteriovenous malformations: causes, clinical presentation, technique and outcomes Educational Exhibit Abstract No. 431 Treating complex vascular anomalies with novel techniques. J Vasc Interv Radiol. Elsevier. 2016;25(3):S187.

19. Agustí PB, Bordes ST, Barrachina IA, Bordes T, Pérez PP, Reyes M, et al. Clinical cases uterine arteriovenous malformation. About a Case. 2016;81(5):406-10.

Cite this article as: Sánchez RDL, Miranda AJR, Flores SEH, Alvarez TP, Cabrera JMB, Huerta AL. Arteriovenous uterine malformation: case report. Int J Reprod Contracept Obstet Gynecol 2020;9:409-14. 